\title{
SIMULATION OF THE IMPACT OF THE SOIL FRICTION ON THE DRAFT RESISTANCE OF THE PLOUGH BODY
}

\author{
Arvids Vilde and Adolfs Rucins \\ Latvia University of Agriculture, Research Institute of Agricultural Machinery \\ 1 Instituta Street, Ulbroka, LV-2130, Latvia \\ e-mail: vilde@delfi.lv; arucins@delfi.lv
}

\section{KEYWORDS}

Plough body's draft resistance, friction resistance, analytic correlations, optimisation of parameters.

\begin{abstract}
By using analytical correlations derived as a result of theoretical research, a computer algorithm has been worked out for simulating the functions of the plough body and the forces exerted by soil upon the operating parts, as well as its draft resistance. These correlations allow to determine the draft resistance of the plough depending on the parameters of its body, as well as to evaluate the impact of the physical and mechanical properties of soil, such as friction upon it. The greatest influence upon the draft resistance is exerted by soil hardness, density and slip resistance along the surfaces of the operating parts. The latter is also affected by soil adhesion, which particularly manifests itself in wet clay soils at lower temperatures. It has been clarified that the friction resistance constitutes $46-62 \%$ of the total draft resistance of the plough body. The main ways of lowering the friction resistance and the total draft resistance of the plough are the introduction of a more rational design of its body having optimum parameters, decreasing the resistance of the share-mouldboard surface and the values of reactions of the supporting surfaces, as well as the application of antifriction materials and better modes of joining with tractors.
\end{abstract}

\section{INTRODUCTION}

It follows from our previous investigations (Vilde 1999, 2003, 2004; Rucins and Vilde 2003, 2004, 2006) that the draft resistance of ploughs depends on the body parameters, the physical and mechanical properties of soil and the working modes. However, there were not enough investigations for analytic assessment of the impact of the body parameters and the variability of soil properties, such as friction, on the variations in the ploughing resistance. This encumbers the calculation of the proper solution of the plough body design and raising the ploughing efficiency.

The purpose of these investigations was analytical assessment of the impact of the variability of the plough body parameters and the soil friction properties on the variations in the ploughing resistance in order to determine the optimal body design under particular soil conditions to improve the ploughing efficiency.

\section{MATERIALS AND METHODS}

The objects of the research are the forces acting on the plough body and its draft resistance depending on the body design parameters, as well as the physical and mechanical properties of soil and the working modes. On the basis of previous investigations, a computer algorithm has been worked out for the simulation of the forces exerted by soil upon the operating (lifting and supporting) surfaces of the plough body, and the draft resistance caused by these forces (Fig. 1).

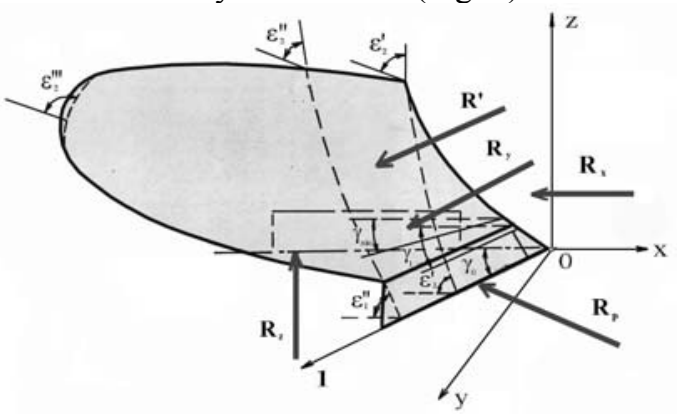

Figure 1. Scheme of the plough body, its parameters and acting forces.

According to our previous investigations (Vilde 1999) the draft resistance $R_{x}$ of the plough body is determined by the share of the cutting resistance $R_{P x}$, the resistance caused by the gravity (weight) $R_{G x}$ of the soil slice lifted, by the inertia forces $R_{J x}$, by soil adhesion $R_{A x}$ and by weight $R_{Q x}$ of the plough body itself (including a part of the weight of the plough).

$$
R_{x}=\sum R_{i x}=R_{P x}+R_{G x}+R_{J x}+R_{A x}+R_{Q x}
$$

The vertical reaction $R_{z}$ and the lateral reaction $R_{y}$ of the operating part are defined by corresponding partial reactions:

$R_{z}=\Sigma R_{i z} ; \quad R_{y}=\Sigma R_{i y}$

The total draft resistance $R_{x}$ of the operating part is composed of the resistance of the working surface $R_{x}$ and the resistance of the supporting (lower and lateral) surfaces $R_{x}^{\prime \prime}$ :

$R_{x}=R_{x}^{\prime}+R_{x}^{\prime \prime}==\sum R_{i x}^{\prime}+f_{0}\left(\sum R_{i z}+\sum R_{i y}+p_{A x y} S_{x y}+p_{A x z} S_{x z}\right)$

where: $f_{0}$ is the coefficient of the soil friction along the working and supporting surfaces of the plough body; $p_{A x y}$ and $p_{A x z}-$ the specific adhesion force applied, respectively, to the lower and the lateral supporting surfaces of the body; 
$S_{x y}$ and $S_{x z}-$ the surface area, respectively, of the lower and the lateral supporting surfaces of the body.

The friction resistance $F_{x}$ is a constituent part of these reactions and their components (Rucins et al. 2003), and, by analogy, we can write that

$$
\begin{aligned}
& F_{x}^{\prime}=\sum F_{i x}^{\prime}=F_{P x}^{\prime}+F_{G x}^{\prime}+F_{J x}^{\prime}+F_{A x}^{\prime}+F_{Q x}^{\prime}=R_{x}^{\prime}-R_{x o}^{\prime} \\
& F_{x}^{\prime \prime}=f_{0}\left(R_{z}+R_{y}+p_{A x y} S_{x y}+p_{A x z} S_{x z}\right)=R_{x}^{\prime \prime} \\
& F_{x}=F_{x}^{\prime}+F_{x}^{\prime \prime}
\end{aligned}
$$

The friction resistance of the share-mouldboard surface is defined as the difference between the total resistance (general value of the partial resistance) and resistance $R_{x o}$ in operation without friction $\left(f_{0}=0\right)$.

$F_{i x}=R_{i x}-R_{i x o} ; F_{x}=R_{x}-R_{x o}$

Ratio $\lambda_{F}$ of the friction resistance in the partial and total resistance (reaction) is determined from their correlations:

$\lambda_{F_{i x}}=F_{i x} R_{i x}^{-1}, \quad \lambda_{F_{x}}=F_{x} R_{x}^{-1}$

Ratio $\lambda_{R}$ of the supporting reactions in the partial and total draft resistance is determined from correlation:

$\lambda_{R_{i}}=R_{i} R_{i x}^{-1}$

The cutting resistance $R_{P x}^{\prime}$ is proportional to soil hardness $\rho_{0}$ and the share edge surface area $\omega$ :

$R_{P x}^{\prime}=k_{p} \rho_{0} \omega=k_{p} \rho_{0} i b$,

where: $k_{p}$ is the coefficient involving the impact of the shape of the frontal surface of the ploughshare edge; $i$ and $b-$ the thickness and width of the edge.

It is evident from formula (13) that friction of soil along the edge does not influence the cutting resistance of the edge.

At a sharp ploughshare (the rear bevel is absent)

$R_{P z}=0$

At a blunt (threadbare) ploughshare having a rear bevel the vertical reaction $R_{P z}$ on the hard soils can reach a summary value of vertical reactions, that arise from other forces acting on the share-mouldboard surface (soil gravity and inertia) and the weight $Q$ of the body.

At an inclined ploughshare a lateral reaction $R_{P y}$ arises, its value being affected by the friction reaction.

$R_{P y}=k_{p} \rho_{0} i b \operatorname{ctg}\left(\gamma_{0}+\varphi_{0}\right)$

where: $\gamma_{0}$ is the inclination angle of the edge towards the direction of the movement (the wall of the furrow);

$\varphi_{0}-$ the angle of friction.

When friction is absent, $f_{0}=0, \varphi_{0}=0$ and

$R_{\text {Pyo }}=k_{p} \rho_{0} i b c t g \gamma_{0}$

The friction of soil along the ploughshare edge reduces the lateral pressure of the ploughshare (the pressure of the plough body against the wall of the furrow).
The resistance of the supporting surface

$R_{P x}^{\prime \prime}=k_{p} \rho_{0} i b f_{0} \operatorname{ctg}\left(\gamma_{0}+\varphi_{0}\right)=F_{P x}^{\prime \prime}$

The total cutting resistance is:

$R_{P x}=k_{p} \rho_{0} i b\left[1+f_{0} \operatorname{ctg}\left(\gamma_{0}+\varphi_{0}\right)\right]$

The lateral cutting resistance of the knife is determined by formulae, similar to those for the cutting resistance of the share. Consequently, similar to the above formulae will also be the formulae defining the impact of friction on the total resistance of the knife.

Forces caused by the gravity of the lifting soil slice:

$R_{G x}^{\prime} \approx q \delta g k_{y} r \sin ^{-1} \gamma^{*}$

$*\left\{\left[\left(\sin \gamma \cos \varepsilon_{1}+\cos ^{2} \gamma \sin ^{1} \gamma\right) e^{f_{0} \sin \gamma\left(\varepsilon_{2}-\varepsilon_{1}\right)}-\right.\right.$

$\left.-\left(\sin \gamma \cos \varepsilon_{2}+\cos ^{2} \gamma \sin ^{-1} \gamma\right)\right] \cos \varepsilon_{1}+$

$+\left(\cos \varepsilon_{1} e^{f_{0} \sin \gamma\left(\varepsilon_{2}-\varepsilon_{1}\right)}-\cos \varepsilon_{2}\right)\left(\cos \varepsilon_{1}-\right.$

$\left.-f_{0} \sin \varepsilon_{1} \sin \gamma\right)^{-1} \sin \varepsilon_{1} *$

* $\left.\left[\sin \varepsilon_{1} \sin \gamma+f_{0}\left(\sin ^{2} \gamma \cos \varepsilon_{1}+\cos ^{2} \gamma\right)\right]\right\}$

$R_{G_{y}} \approx q \delta g r \sin ^{-1} \gamma\left(\varepsilon_{2}-\varepsilon_{1}\right)\left(\varepsilon_{1}+0.52\right) \operatorname{ctg} \gamma$

$R_{G_{z}} \approx q \delta g r \sin ^{-1} \gamma\left(\varepsilon_{2}-\varepsilon_{1}\right)$

$R_{G x}^{\prime \prime}=f_{0}\left(R_{G z}+R_{G y}\right)=F_{G x}^{\prime \prime}$

Forces caused by the soil inertia:

$R_{J x}^{\prime}=q \delta v^{2} k_{y}^{-1} \sin \gamma\left\{\left(\sin \gamma \cos \varepsilon_{1}+\cos ^{2} \gamma \sin ^{-1} \gamma\right)^{*}\right.$

$* e^{f_{0} \sin \gamma\left(\varepsilon_{1}-\varepsilon_{2}\right)}-\left(\sin \gamma \cos \varepsilon_{2}+\cos ^{2} \gamma \sin ^{-1} \gamma\right)+$

$+\left(\cos \varepsilon_{1}-f_{0} \sin \varepsilon_{1} \sin \gamma\right)^{-1} e^{f_{0} \sin \gamma\left(\varepsilon_{2}-\varepsilon_{1}\right) *}$

$\left.* \sin \varepsilon_{1}\left[\sin \varepsilon_{1} \sin \gamma+f_{0}\left(\sin ^{2} \gamma \cos \varepsilon_{1}+\cos ^{2} \gamma\right)\right]\right\}$

$R_{J z}=q \delta v^{2} k_{y}^{-1} \sin \gamma \sin \varepsilon_{2} e^{f_{0} \sin \gamma\left(\varepsilon_{2}-\varepsilon_{1}\right)}$

$R_{J y} \approx q \delta v^{2} k_{y}^{-1} \sin \gamma \cos \gamma\left(1-\cos \varepsilon_{2}\right)$

$R_{J x}^{\prime \prime}=f_{0}\left(R_{J z}+R_{J y}\right)=F_{J x}^{\prime \prime}$

Forces caused by soil adhesion:

$R_{A x}^{\prime}=p_{A} b r \sin ^{-1} \gamma\left(e^{f_{0} \sin \gamma\left(\varepsilon_{2}-\varepsilon_{1}\right)}-1\right)^{*}$

$*\left\{\sin \gamma \cos \varepsilon_{1}+\cos ^{2} \gamma \sin ^{-1} \gamma+\left(\cos \varepsilon_{1}-f_{0} \sin \varepsilon_{1} \sin \gamma\right)^{-1} *\right.$

$\left.{ }^{*} \sin \varepsilon_{1}\left[\sin \varepsilon_{1} \sin \gamma+f_{0}\left(\sin ^{2} \gamma \cos \varepsilon_{1}+\cos ^{2} \gamma\right)\right]\right\}$

$R_{A z}=0 ; \quad R_{A y} \approx 0$;

$R_{A x}^{\prime \prime}=f_{0}\left(p_{A x y} S_{x y}+p_{A x z} S_{x z}\right)=F_{A x}^{\prime \prime}$

where: $q-$ the cross section area of the soil slice; $\delta$ - the density of soil;

$k_{y}$ - the soil compaction coefficient in front of the operating part;

$f_{0}$ - the soil friction coefficient against the surface of the operating element;

$v$ - the speed of the movement of the plough body;

$p_{A}$ - the specific force of soil adhesion;

$b$ - the surface width of the soil slice;

$\varepsilon_{1}$ and $\varepsilon_{2}$ are correspondingly the initial and the final angles of the lifting (share- mouldboard) surface; $g-$ acceleration caused by gravity $(g=9.81)$. 
The draft resistance caused by the body's weight:

$R_{Q x}^{\prime \prime}=Q f_{0}$

where: $Q$ - the weight of the plough body (including a part of the weight of the plough).

The soil friction coefficient and the specific force of soil adhesion are not constant values. Their values decrease with the increase in speed (Rucins at al., 2003). This is considered in calculations.

The resistance of the supporting surfaces of the plough body depends on the values of the reacting forces. Yet their value is dependent, in many respects, on the manner of unification and perfection of the hydraulically mounted implements of the tractor. The vertical reaction of the plough with modern tractors having power regulation is transferred to the body of the tractor, and it affects the plough resistance to a considerably lesser degree. There are also solutions for the reduction of the lateral reaction. In such a way, the dominating component of the draft resistance of the plough body is the resistance of its share-mouldboard surface, to the research of which the present work is mainly devoted.

\section{RESULTS AND DISCUSSION}

The presented work discusses, as an example, the simulation results of the impact of the body parameters, the physical and mechanical properties of soil, such as the soil friction and the working modes on the draft resistance of the plough body at various initial lifting angles $\varepsilon_{l}$, and at various angles $\gamma$ of the horizontal generatrices, and at various working widths depending on the speed of operation when ploughing, for example, loamy soils, which predominate in Latvia.

Calculations were carried out with a computer according to the foregoing formulae.

The following values of the basic factors were taken into consideration affecting the resistance of the sharemouldboard surface and the plough body.

The parameters of the plough body:

The thickness of the share blade and knife $\quad i=0.004 \mathrm{~m}$

The initial angle of the lifted strip of soil $\quad \varepsilon_{1}=30^{\circ}$

The final angle of the lifted strip of soil $\quad \varepsilon_{2}=100^{\circ}$

The inclination angle of the horizontal generatrix

$$
\gamma=35^{0} \ldots 45^{0}
$$

The radius of the curvature of the lifting surface

$$
r=0.5 \mathrm{~m}
$$

The area of the lower supporting surface $S_{x y}=0.0157 \mathrm{~m}^{2}$

The area of the lateral supporting surface $S_{x z}=0.068 \mathrm{~m}^{2}$ The weight of the plough body $Q=200 \mathrm{~kg}$

The physical and mechanical properties of soil:

The hardness of soil

The density of soil

$\rho=4.1 \mathrm{mPa}$

The coefficient of soil friction

The adhesion force
The mode and status of work:

The ploughing depth

The working width of the body

The cross section area of the soil slice

The soil compaction coefficient in front

of the share-mouldboard surface

The working speed

$$
\begin{array}{r}
a=0.20 \mathrm{~m} \\
b=0.35 \mathrm{~m} \\
q=0.07 \mathrm{~m}^{2} \\
\\
k_{y}=1.1 \\
v=1 \ldots .5 \mathrm{~m} \mathrm{~s}^{-1}
\end{array}
$$

The inclination angle $\gamma$ of the horizontal generatrix of the real share-mouldboard surfaces of the plough bodies lies between $26^{0} \ldots 50^{\circ}$. Steeper surfaces $\left(\gamma>50^{\circ}\right)$ refer to the slanting blades of bulldozers.

As an example, the calculation results of the impact of the soil friction coefficient $f_{0}$ upon the draft resistance of the plough body share-mouldboard (lifting) surface, as well as reacting forces on the supporting surfaces, the draft resistance and the total draft resistance of the entire plough body at the inclination angle $\varepsilon_{1}=30^{\circ}$ of the share (initial soil slice lifting angle), at the inclination angle $\gamma=35^{\circ} \ldots 45^{\circ}$ of the horizontal generatrix and at various speeds $v$ are presented in the following graphs.

The draft resistance of the lifting (share-mouldboard) surface and its components are presented in Figs. 2 - 5, the reacting forces on the supporting surfaces - in Figs. $6-10$, the draft resistances of the supporting surfaces in Fig. 11, and the total draft resistance of the plough body - in Fig. 12.

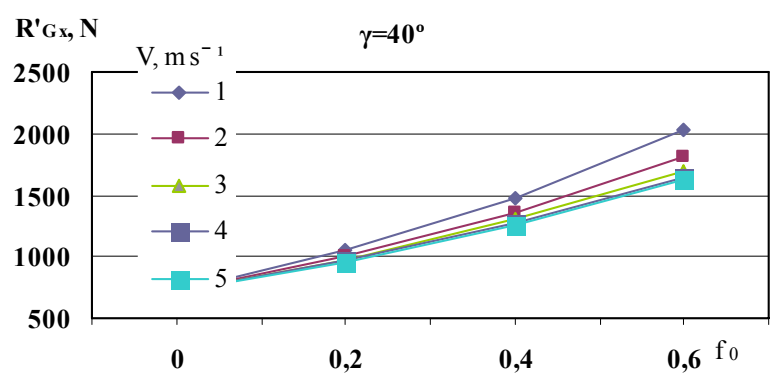

Fig.2. Impact of the soil friction coefficient $f_{0}$ upon the draft resistance of the plough body share-mouldboard surface caused by the gravity of the soil slice.

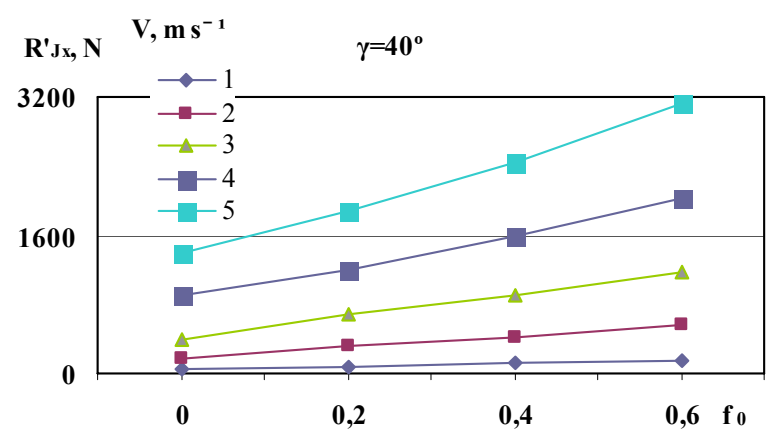

Fig.3. Impact of the soil friction coefficient $f_{0}$ upon the draft resistance of the plough body share-mouldboard surface caused by the soil inertia forces. 


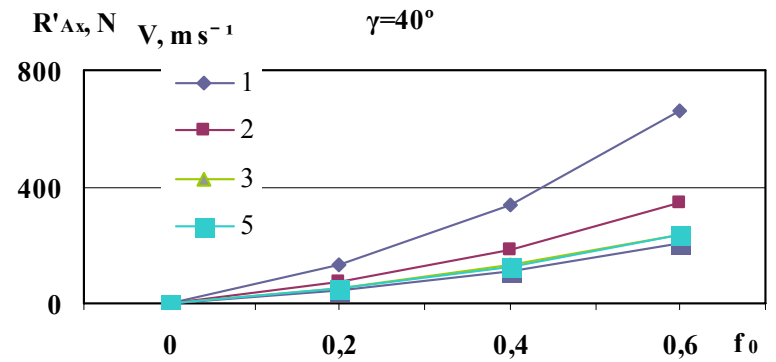

Fig.4. Impact of the soil friction coefficient $f_{0}$ upon the draft resistance of the plough body share-mouldboard surface caused by adhesion.
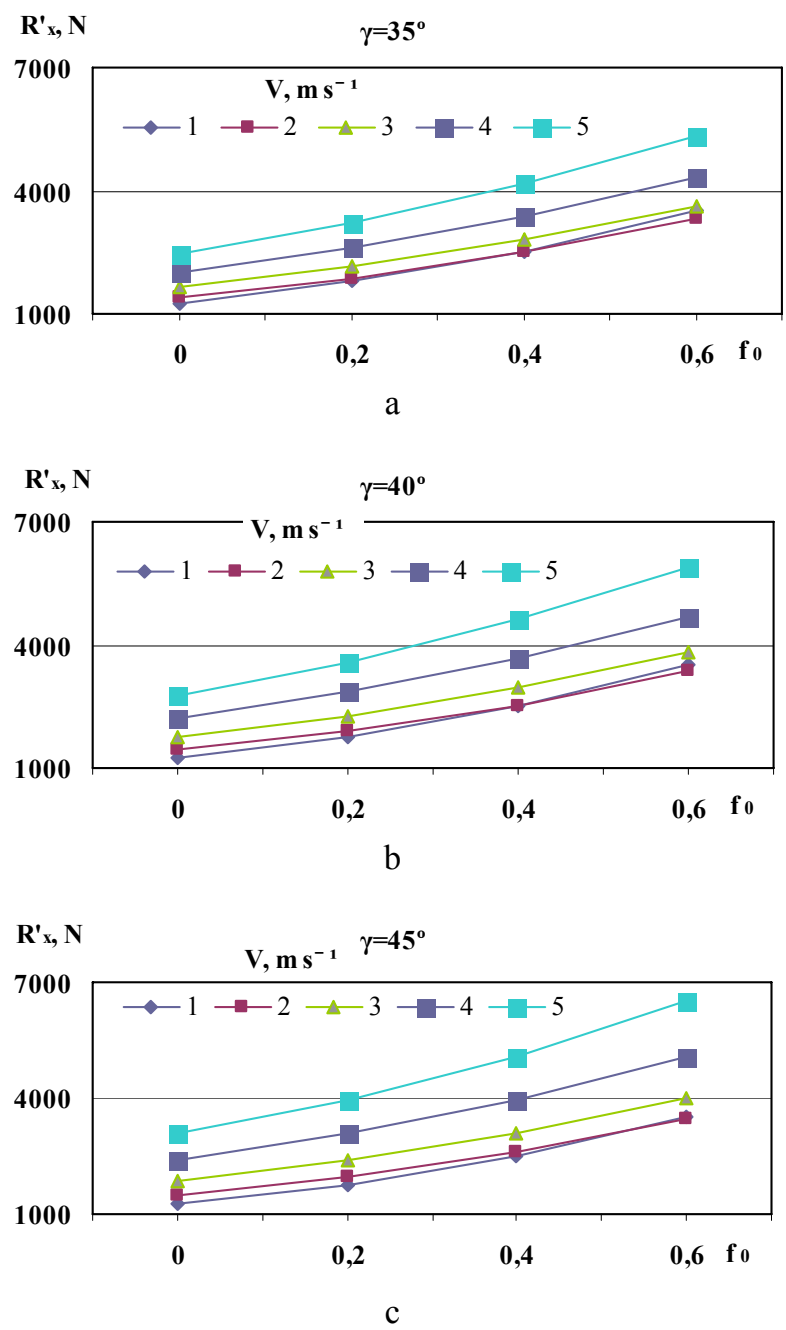

Fig.5. Impact of the soil friction coefficient $f_{0}$ upon the total draft resistance of the plough body sharemouldboard surface caused by the soil gravity, the inertia forces, adhesion and soil cutting resistance at the inclination angle $\gamma$ of the horizontal generatrix:

$$
\mathrm{a}-\gamma=35^{\circ} ; \mathrm{b}-\gamma=40^{\circ} ; \mathrm{c}-\gamma=45^{\circ}
$$

From the graphs above (Figs, 2-5) it follows that at the soil friction coefficient $f_{0}=0.3 \ldots 0.4$ and at the speed $v=2 \ldots 3 \mathrm{~m} \mathrm{~s}^{-1}$, presently predominating in ploughing, the draft resistance caused by the soil friction takes $36 . .42 \%$ of the total draft resistance of the sharemouldboard surface.

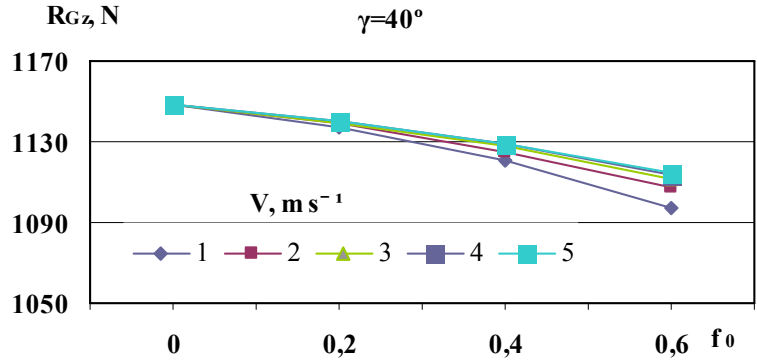

Fig.6. Impact of the soil friction coefficient $f_{0}$ upon the vertical reaction of the plough body caused by the gravity of the soil slice.

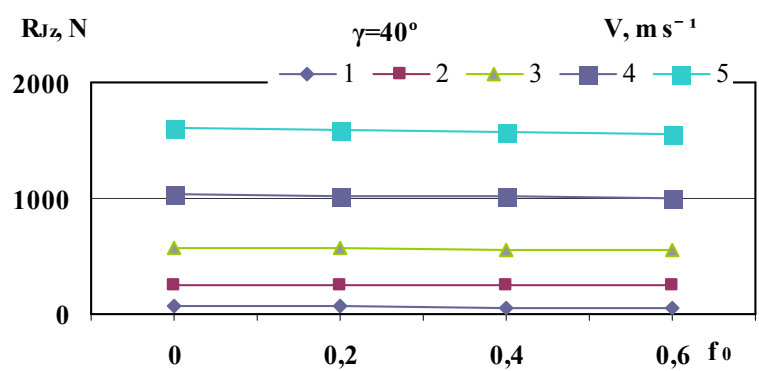

Fig.7. Impact of the soil friction coefficient $f_{0}$ upon the vertical reaction of the plough body caused by the inertia forces of the soil slice.

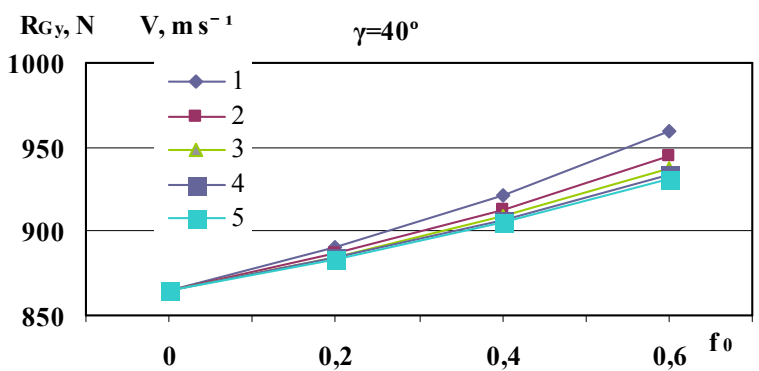

Fig.8. Impact of the soil friction coefficient $f_{0}$ upon the lateral reaction of the plough body caused by the gravity of the soil slice.

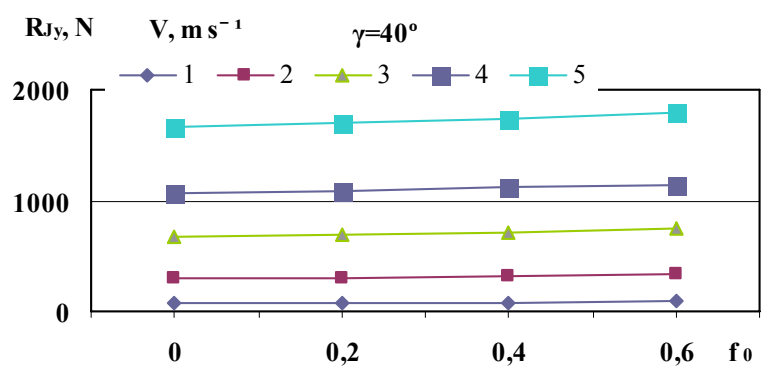

Fig.9. Impact of the soil friction coefficient $f_{0}$ upon the lateral reaction of the plough body caused by the inertia forces of the soil slice.

The calculations and graphs above (Figs. 6-9) show that the value of the soil friction caused at the soil slice gravity, inertia forces and adhesion has only a little influence on the reactions of the supporting surfaces. 




Fig.10. Impact of the soil friction coefficient $f_{0}$ upon the lateral reaction caused by the soil cutting with the plough share at the inclination angle of the cutting edge $\gamma_{0}=40^{\circ}$.

The graph above (Fig. 10) shows that at the values of the friction coefficient $f_{0}=0.3 \ldots 0.4$ the lateral reaction caused by the soil cutting decreases on $36 \ldots 55 \%$.
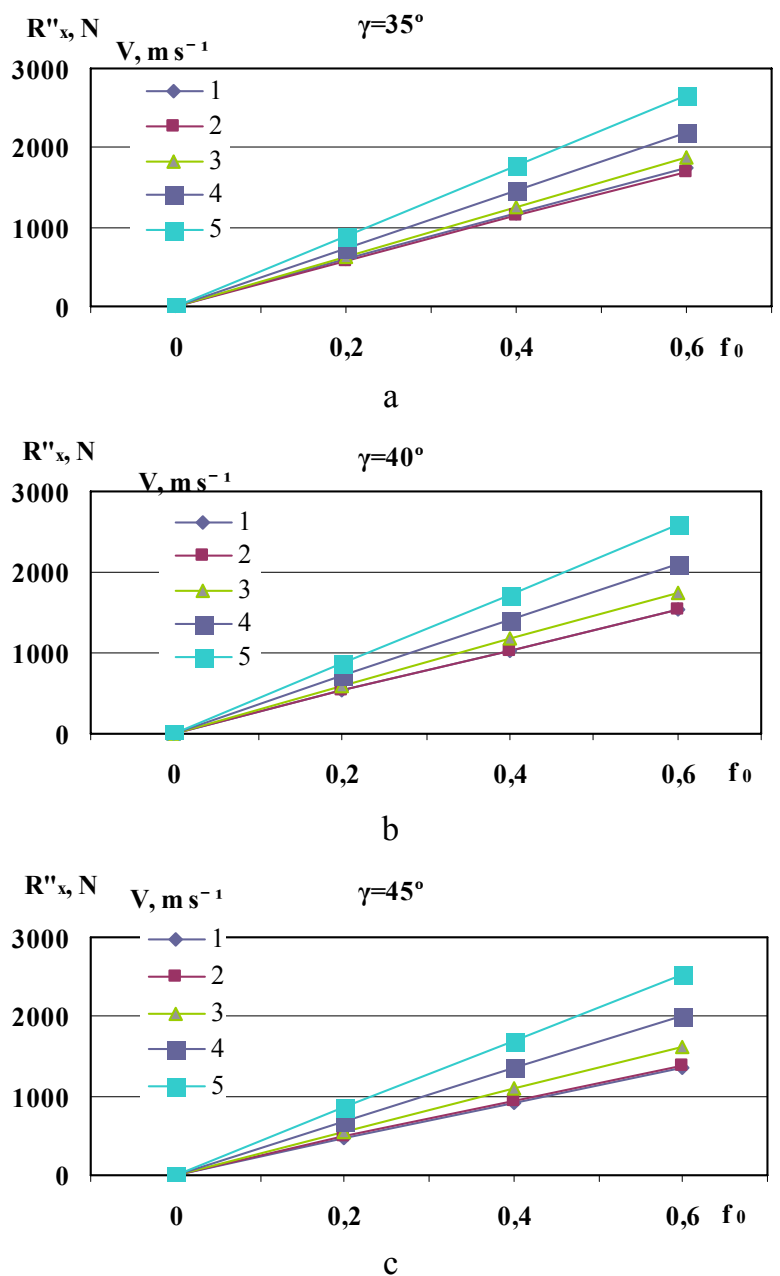

Fig.11. Impact of the soil friction coefficient $f_{0}$ upon the draft resistance of the supporting surfaces of the plough body: $\mathrm{a}-\gamma=35^{\circ} ; \mathrm{b}-\gamma=40^{\circ} ; \mathrm{c}-\gamma=45^{\circ}$.

It follows from the graphs above (Fig. 11) that the increase in speed increases the draft resistance of the supporting surfaces caused by soil friction. The value of the inclination angle of the horizontal genetratrix $\gamma$ at the interval $\gamma=35^{\circ} \ldots 45^{\circ}$ has only a little influence on the draft resistance of the supporting surfaces.


Fig.12. Impact of the soil friction coefficient $f_{0}$ upon the total draft resistance of the plough body:

$$
\mathrm{a}-\gamma=35^{\circ} ; \mathrm{b}-\gamma=40^{\circ} ; \mathrm{c}-\gamma=45^{\circ}
$$

It follows from the graphs above (Fig. 12) that at the values of the friction coefficient $f_{0}=0.3 \ldots 0.4$ the draft resistance caused by the soil friction takes $46 \ldots 62 \%$ of the total draft resistance of the plough body. It follows that the total draft resistance is approximately proportional to the friction coefficient. Increasing the speed decreases the share (ratio $\lambda_{F}$ ) of the friction resistance in the total draft resistance of the plough body. This phenomenon can be explained by the decreasing value of the friction coefficient when the speed is increasing (Vilde et al. 2007).

From the graphs (Fig. 12) it is evident too that at the values of the friction coefficient $f_{0}=0.3 \ldots 0.4$ increasing the inclination angle of the horizontal genetratrix $\gamma$ in the interval $\gamma=35^{\circ} \ldots 45^{\circ}$ increases the draft resistance of the plough body to $6 \ldots 10 \%$. This phenomenon is in agreement with the previous conclusions that the optimal values for the inclination angle of the horizontal genetratrix $\gamma$ on the initial part of the share-mouldboard surface are $34 \ldots 38^{0}$ (Rucins and Vilde 2007).

It follows from formulas (17) - (30), too, that increasing the initial lifting angle $\varepsilon_{l}$ increases the draft resistance of the share-mouldboard surface, including the resistance of the soil friction (Rucins at al. 2007), but increasing the 
working width of the body decreases the specific draft resistance of ploughing (Rucins and Vilde 2005). It was established from them that the optimal values of the initial lifting angle are $\varepsilon_{1}=28 \ldots 32^{\circ}$ and the optimal working width of the plough body $-b=45 . .50 \mathrm{~cm}$.

From the presented example it is evident that the draft resistance of the supporting surfaces is considerable. It can reach $25 \ldots 30 \%$ of the total plough body draft resistance, or $36 \ldots 44 \%$ of its share-mouldboard draft resistance (Figs. 5, 11, 12).

Therefore it is very important for the reduction of the energy consumption of ploughing to reduce the draft resistance of the supporting surfaces. It may be obtained by using a contemporary hang-up device with the tractors, for example, power regulation allowing the transfer of the vertical reactions of the plough to the body of the tractor (Vilde et al. 2004). It may decrease the draft resistance of the ploughs to $6 \ldots 10 \%$.

In the sources provided by other authors there are no materials about the application of the simulation methods in order to study the impact of the plough body parameters, as well as the soil friction properties on the draft resistance of the plough bodies. In order to obtain a better design of the plough body, a series of different bodies were built and tested (Larsen 1968, Burchenko et al. 1976, Burchenko 2001, Nikiforov and Ivanov 1973). Yet it is bound with a great loss of resources, labour and time, so the best solution of the compared variants may not always be the optimum ones.

The materials of our investigations carried out by using the correlations indicated above present the values and regularity of the changes in the forces, the soil friction, acting on the share-mouldboard and the supporting surfaces, the draft resistance of the share-mouldboard and the supporting surfaces, as well as the total resistance of the plough body and its components under the working conditions depending on the body parameters, the soil friction coefficient and the working speed. In such a way it is possible to discover the draft resistance structure of the body, to assess the ratio of each element in the total resistance, to search and find possibilities how to reduce the tillage energy requirement.

\section{CONCLUSIONS}

1. The deduced analytical correlations and the developed computer algorithm allow simulation of the soil coercion forces upon the operating surfaces of the plough body, determination of the draft resistance and the optimal values of parameters, as well as the impact of the soil friction properties.

2. Presentation of the plough body draft resistance as the sum of its components - the cutting resistance of the soil slice, the resistance caused by its gravity, the soil inertia forces and adhesion including the soil friction resistance allows analysing the forces acting upon the sharemouldboard and the supporting surfaces, finding out the character of their changes depending on the soil properties, parameters of the surfaces, of working speed, assessment of their ratio in the total resistance and determination of the optimal parameters of the body.

3 . Increase in the inclination of the horizontal generatrix leads to a decrease in the draft resistance caused by the weight, adhesion and friction of the soil but it increases the resistance caused by the inertia forces, particularly, when the speed increases. The inclination of the generatrix (the edge of the share) does not affect the cutting resistance of the soil slice.

4. The impact of the soil-metal friction upon the draft resistance of the plough body is significant. It may reach $46 \ldots 62 \%$ of the total draft resistance including the resistances of the supporting surfaces $(25 \ldots 30 \%)$. Therefore measures will be taken to diminish it, for example, by improving the body design, improving the mode of aggregation (joining) with tractors, using antifriction materials. The relief of the lower supporting surface may diminish the draft resistance of the body caused from the soil friction to $6 \ldots 10 \%$.

5. The optimal values of the main parameters of the body for contemporary ploughs, working at the speeds of $2 \ldots 2.5 \mathrm{~m} \mathrm{~s}^{-1}$ are: the inclination angle of the share towards the furrow bottom $-28 \ldots 32^{0}$; the inclination angle of the horizontal generatrix towards the furrow wall on the initial part of the share-mouldboard surface $-34 \ldots 38^{0}$, on the top - not less than $48^{0}$; the working width of the bottom $-45 \ldots .50 \mathrm{~cm}$.

6. The use of bodies having optimal parameters allows obtaining a good ploughing quality, reduction of the draft resistance by $12 \ldots 20 \%$ and a corresponding rise in the efficiency, saving fuel and financial means.

7. Further, in such a way it is possible to carry out the simulation of the impact of the soil moisture, as well as of the other soil properties, on the work and the draft resistance of the ploughs with aim to find out the favourable soil conditions for efficient ploughing.

\section{REFERENCES}

Vilde A. 1999. "Dynamics of the soil tillage machine operating parts and their elements". Proceedings of the Latvia University of Agriculture, Vol.1 (295). Jelgava, Latvia, 36-44.

Vilde A. 2004. "Mechanical and mathematical foundations for modelling the dynamics of soil tillage machine operating parts". TEKA Commission of Motorization and Power Industry in Agriculture, Volume IV. Polish Academy of Sciences Branch in Lublin. Lublin, Poland, 228-236.

Rucins, A. and A. Vilde. 2004. "Mathematical modelling of the operation of plough bodies to determine their draft resistance and optimum parameters". TEKA Commission of Motorization and Power Industry in Agriculture, Volume IV. Polish Academy of Sciences Branch in Lublin. Lublin, Poland, 177-184.

Rucins, A.; A. Vilde and W. Tanas'. 2006. "Forces acting on a plough body". TEKA Commision of Motorization and Power Industry in Agriculture, Volume VI. Polish Academy of Sciences Branch in Lublin. Lublin, Poland, 135-145.

Rucins, A. and A. Vilde. 2005. "Modelling forces acting on the plough body". Simulation in Wider Europe. $19^{\text {th }}$ 
European Conference on modelling and Simulation ECMS 2005 June 1-4, 2005 Riga, Latvia. Riga, 414-419.

Rucins, A.; A. Vilde and J. Nowak. 2007. "Impact of the share inclination angle on the ploughing resistance". TEKA Commission of Motorization and Power Industry in Agriculture, Volume VII. Polish Academy of Sciences Branch in Lublin, Lublin, Poland, 199 - 209.

Rucins, A. and A. Vilde. 2005. "Plough body working width optimization". Recent results and future challenges in soil tillage research. International scientific seminar Reports. Akademija, Lithuania, 69-75.

Vilde A. 2003. "The impact of soil moisture and composition on its properties and energy consumption of tillage". TEKA Commission of Motorization and Power Industry in Agriculture, Volume III. Polish Academy of Sciences Branch in Lublin. Lublin, Poland, 249 - 255.

Vilde A. 2001. "Physical and mechanical properties of soil affecting energy capacity of its tillage". Proceedings of the $I^{\text {st }}$ International Conference of BSB of ISTRO "Modern ways of soil tillage and assessment of soil compaction and seedbed quality" - 21-24 August 2001. EAU, Tartu, Estonia, 97-106.

Rucins, A., and A. Vilde. 2003. "Impact of soil-metal friction on the draft resistance of ploughs" Research for rural development 2003. International scientific conference proceedings Jelgava, Latvia 21-24 May, 2003. Jelgava, Latvia University of agriculture, 61-63.

Vilde, A.; S. Cesnieks and A. Rucins. 2004. "Minimisation of soil tillage". TEKA Commission of Motorization and Power Industry in Agriculture, Volume IV. Polish Academy of Sciences Branch in Lublin. Lublin, Poland, 237-242.

Rucins, A. and A. Vilde. 2007. "Impact of the Plough Body Parameters on the Ploughing Efficiency". Ecology and Agricultural Machinery. Proceedings of the $5^{\text {th }}$ International Scientific and Practical Conference, May, 15-16, 2007, Vol. 2. Saint Petersburg-Pavlovsk, 2007, $282-290$.

Vilde, A.; A. Rucins and G. Sevostjanovs. 2007. "Impact of Speed on the Soil Sliding Resistance". International Conference "Technical and Technological Progress in Agriculture", No 12, 20-21 September 2007. Raudondvaris, Lithuania, 34-38.

Larsen, L.W.; W.G. Lovely and C.W. Bockup. 1968. "Predicting draught forces using model mouldboard ploughs in agricultural soils". Trans. American Society of Agricultural Engineers, 11, 665-668.

Burchenko, P.N.; A.N. Ivanov; B.A. Kashajev; V.G. Kirjuhin and A.I Miltsev. 1976. "Resultaty issledovanija rabochih organov skorostnyh plugov." In Povyshenie rabochih skorostjei mashinno-traktornyh agregatov. Moscow, Kolos, 215-218. (In Russian). "Results of the investigation of the working parts of high-speed ploughs".

Burchenko, P.N. 2001. " $\mathrm{K}$ teoryi razvertivajusheisja lemeshno-otvaljnoi poverhnosti korpusa pluga". In mashinnye tehnologii i tehnika dlja proizvodstva zernovih, maslichnih $i$ zernobobovih kultur. Tom 3, chastj 1. Moscow, VIM, 38-51. (In Russian). "Belonging to the theory of the roll out share-mouldboard surface of the plough body".

Nikiforov, P.E. and A.N. Ivanov. 1973. "Issledovanije rabochih organov plugov dlja raboty so skorostjami 10-15 $\mathrm{km} / \mathrm{h}$ ". In Povyshenie rabochih ckorostjei mashinnotraktornyh agregatov. Moscow, CINTIAM, 197-203. (In Russian). "Investigation of the working parts of ploughs for working at the speeds of $10-15 \mathrm{~km} / \mathrm{h}$ ".

\section{AUTHOR BIOGRAPHIES}

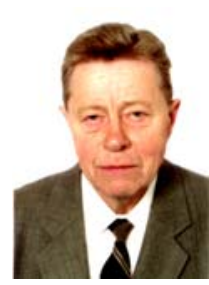

ARVIDS A. VILDE was born in 1929 in Bauska, Latvia, in a farmer's family. After finishing a secondary school he entered the Latvia Academy of Agriculture, where he studied Agricultural Machinery and obtained the degree of an engineer in 1954. Subsequently he obtained the following degrees: Candidate of Technical Sciences (SU) in 1965, Doctor of Technical Sciences (SU) in 1986, Doctor habil. sc. ing. in 1992. He worked for 5 years as the chief engineer in the field of agricultural machinery and production. Since 1960 up to this time he is engaged in the leading research groups in Latvia Research Institute of Agricultural Machinery. The research branches: soil dynamics in tillage, including the dynamic properties of soil; technology, machines and units for soil tillage and sugar beet growing, their rationalization and perfection; the use of big high-speed tractors and machines; energy requirements for field crop production and ways of it reduction; normative requirements for tractors and machines, their working load and fuel consumption. Now he is leading the research in Precision Agriculture using the GPS, and in the plant spacing simulation by sowing seeds at exact intervals, as well as in the simulation of forces acting on the plough body in order to determine its draft resistance and optimal parameters. A Vilde has received several medals and diplomas at the Exhibition of Economic Achievements in Moscow. In 1985 he received the Latvian State Prize. He was named a Merited Inventor of Latvia in 1990, International Man of the Year for 2000-01 and a Latvian State Emeritus Scientist 2001. He is an expert of promotion councils and a publicist who has written more than 800 publications including eighteen monographs. He enjoys orchards and stenography.

His e-mail address is vilde@delfi.lv

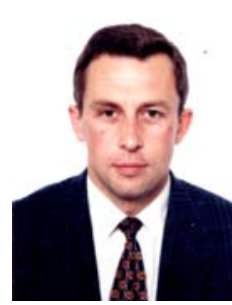

ADOLFS A. RUCINS was born in 1962 in Riga, Latvia. After finishing the Latvian Industrial Polytechnical School he entered the Latvia Technical University, where he studied Machinery and obtained his engineer degree in 1989. Subsequently he obtained the Degree of a Doctor sc. ing. in 2008. He worked for 3 years as a lecturer at the Latvian Technical University. Since 1992, up to this time he is a researcher at the Latvian Research Institute of Agricultural Machinery.

The research branches: technology, machines and units for soil tillage and grain sowing. Now he takes part in the research works in Precision Agriculture using the GPS, as well as simulation of the forces acting on the plough body, in order to determine its draft resistance and optimal parameters. He has also written 67 publications.

His e-mail address is arucins@delfi.lv 